Revista Iberoamericana, Vol. LXVIII, Núm. 200, Julio-Septiembre 2002, 897-906

\title{
UN DEBATE LATINOAMERICANO SOBRE PRÁCTICA INTELECTUAL Y DISCURSO CRÍTICO
}

\author{
POR \\ Nelly Richard \\ Revista de Crítica Cultural
}

No me interesa demasiado especular sobre si existen razones de más o razones de menos para anunciar o bien lamentar el "fin" de "la" (¿cuál?) crítica latinoamericana. ${ }^{1}$ Quisiera más bien revisar ciertos contornos del debate teórico-intelectual que ha estado animando una determinada escena de reflexión en América Latina, para extraer de ella algunas preguntas que conciernen a la relación entre saberes académicos, texto crítico y estrategias de intervención político-intelectuales.

¿Cuáles son los actuales límites de validez y eficacia sociales de las operaciones de la crítica en contextos de saturación mediática, de liviandad comunicacional, de estandarización del consumo simbólico, de funcionalización y burocratización del saber, y también —en nuestros contextos posdictatoriales- de sutura antiutópica del presente en nombre de la razonabilidad democrática?

¿Cuáles son las condiciones — enunciativas y comunicativas - bajo las cuales la crítica intelectual puede aún desplegar sus estrategias de intervención social, en el caso de no resignarse al mundo de la exclusiva profesionalización académica?

¿Qué valor de resistencia poseen los giros metacríticos de una práctica del texto que desea seguir indagando en los dobleces de la subjetividad y el pensamiento para, desde las vueltas y rodeos de la palabra escrita, oponerse al lugar común de la transparencia mediática?

Es muy difícil que una microescena de pensamiento crítico que debate consigo misma alrededor de las marcas de la posdictadura en Argentina y en Chile, adquiera visibilidad en el mundo de los congresos del latinoamericanismo internacional. Lo sabemos, la "funcióncentro" del eje de reproducción y transferencia académico-metropolitanas hace que, muchas veces, sólo se reconozcan como válidos, para efectos de la discusión internacional, aquellos discursos que se ciñen linealmente a las demarcaciones de categorías y objetos ya recortados por el diseño globalizante de la industria universitaria. Es así como el eje de reproducción académica dominante sacrifica la densidad reflexiva de ciertos pliegues más esquivos o reticentes que no entran en directa correspondencia de éxito con los temas de alta visibilidad.

Quisiera evitar aquí las grandes líneas de referencia que suelen monopolizar el debate Norte-Sur en torno a los estudios culturales (poscolonialismo, subalternidad, hibridez, etc.),

\footnotetext{
${ }^{1}$ Hago aquí alusión al título de la mesa ("The end/s of Latin American Criticism”) en el que presenté esta ponencia: LASA (Latin American Studies Associaton) 2000-Miami (16-18 de marzo).
} 
para detenerme en subtrazados más tenues e inquisitos que recorren con detallada insistencia una particular escena de reflexión crítica en Argentina y en Chile. Estos subtrazados, a su vez diversificados según las respectivas configuraciones políticas y culturales de los campos argentino y chileno, resultan especialmente desafiantes para reflexionar sobre las actuales transformaciones de la práctica intelectual en tiempos no sólo de mutación de las disciplinas en el interior de la academia sino también, en su exterior, de neoliberalización del conocimiento y de pluralización indiferenciada del valor cultural por culpa de la promiscuidad banal del mercado.

INTELECTUALES Y SOCIEDAD: DE LA COMUNIDAD DE SENTIDO A LAS RUPTURAS DE VOZ

Casi todos los discursos de este fin de siglo comentan las amenazas que hace pesar sobre la función intelectual la dominante neoliberal, con sus dispositivos de reducción y traducción de los signos a la lógica — económica y comunicativa — del mercado. Las razones para evocar estas amenazas son ampliamente conocidas, y sólo enumero aquí las principales:

1) la crisis de los fundamentos modernos (totalidad, generalidad, universalidad) que garantizaban la autoridad de la función intelectual para enunciar la Verdad de una toma de conciencia colectiva que se ha vuelto obsoleta en el paisaje de hoy, un paisaje dominado por el fragmentarismo y el particularismo de valores, gustos y opiniones, todos ellos nivelados entre sí por el relativismo de la diversidad;

2) la creciente tecnificación de lo social que suprime la conflictualidad de lo político y disuelve la materia ideológica de donde el intelectual de antes extraía sus argumentos de confrontación al poder; la consagración profesional del conocimiento útil y del saber aplicado que ejerce la figura tecnocrática del experto, una figura que ha depuesto las armas de la crítica para entrar al servicio de la planificación administrativa del orden y racionalizar así los desajustes simbólicos y expresivos de ese orden en una lengua de simples ajustes numerarios y funcionarios;

3) la comercialización publicitaria del mercado simbólico cuyos estereotipos de recepción uniforman nuestra percepción cultural con sus vocabularios seriados; la hegemonía mediática de los lenguajes audiovisuales que, al descentrar el canon erudito de la "ciudad letrada” cuyo descriframiento era tarea reservada del intelectual moderno, pusieron a este último en crisis de rol y función.

Éstos son algunos de los términos acordados para realizar un diagnóstico de fin de siglo en el que participan varios intelectuales latinoamericanos. ${ }^{2}$ Pero si bien este diagnóstico es mayoritariamente compartido, las alternativas de respuestas a sus desafíos son a menudo divergentes tal como lo muestra una reciente polémica escrita entre Horacio González y Beatriz Sarlo: una polémica que (coincido con Judith Podlune) constituye "uno de los debates críticos más fértiles de la década” (67). ${ }^{3}$

\footnotetext{
${ }^{2}$ Para una muy seria y lúcida revisión de estos términos, ver: Graciela Montaldo, "Intelectuales y artistas en la sociedad civil argentina en el fin de siglo”. También aporta a la misma discusión el siguiente texto: Andrea Pagni y Erna von der Walde: “¿Qué intelectuales en tiempos posmodernos o de cómo ser radical sin ser fundamentalista?”

${ }^{3}$ Judith Podlune realiza una muy aguda lectura de la tensión que enfrenta a ambos autores en: "Beatriz Sarlo/Horacio González: Perspectivas de la crítica cultural”. La polémica en cuestión se ha dado a
} 
Si me interesa comentar algunos de los aspectos de esta polémica no es sólo por el rigor y la exigencia del problema intelectual que articulan estas dos figuras de la crítica argentina, sino también por los ecos - muy familiares - que proyecta este debate en nuestra escena de discusión chilena. Más allá de los dos nombres principales que abren directamente el debate, comparecen en sus redes cómplices muchas otras voces chilenas y argentinas de las que testimonian las citas que acompañan mi texto.

Revisemos, entonces, algunas facetas de la polémica, comenzando por subrayar lo que une a Sarlo y González. Ambos autores poseen en común la voluntad de desbordar las fronteras académicas de departamentalización del conocimiento: el deseo de impulsar la crítica a romper con las marcas de especialización disciplinaria que mantienen el saber cautivo de sus protocolos de transmisión académica. Sarlo y González comparten, además, el deseo de explorar nuevas condiciones de enunciación para que la voz crítica se oponga, por un lado, al realismo práctico del saber instrumentalizado de los expertos y, por otro lado, al sentido común del mercado cultural y sus trivializaciones comunicativas.

Contestar los mecanismos de rendición sumisa de formas y subjetividades entregadas al despliegue neoliberal, pasaría por formular "interrogantes cuya pretensión sea perturbar las justificaciones celebratorias o cínicas de lo existente” (Sarlo, Escenas de 10). Si bien la cita es de B. Sarlo, ambos autores podrían compartir su misma formulación, auque no los modos de ejecutarla. En el caso de Sarlo, la voluntad de perturbación crítica de las versiones autosatisfechas con las que habla el presente no se desliga de las articulaciones sociales de la experiencia colectiva. Se trataría, para ella, de mantener un diálogo vivo y alerta con las expresiones más cotidianas del presente (del shopping center a los video games) y con las nuevas prácticas ciudadanas que modulan cambios en la sociedad civil, para seguir interviniendo de manera activa y batallante en las crónicas sociales de lo político. Sin ese diálogo crítico con las formas del presente socialmente compartidas, el intelectual perdería la oportunidad de modificar virtualmente, con su argumentación polémica, el sentido común que debe rebatir y debatir.

Aunque habiendo meditado rigurosamente sobre las lecciones dejadas por la crisis del intelectual moderno (y por la crisis de sus fundamentos de "autonomía” y "distancia crítica”), B. Sarlo sigue defendiendo un rasgo articulador de la tradición intelectual moderna: la evocación de una totalidad social que, pese a haber sido liberada de su peso determinista, sigue funcionando como un horizonte general de inscripción y debate de las ideas. Sin ese horizonte general, la confrontación de ideas se reduciría al particularismo de disgregados “juegos de lenguajes” con sus efectos meramente zonales. Para B. Sarlo, sigue siendo insuprimible la desgarrada tensión entre, por un lado, la regionalidad o sectorialidad de los delimitados espacios de intervención teórica que nos reserva el quiebre posmoderno de una verdad que ya no podemos llamar universal y, por otro lado, la necesaria referencia de la palabra del intelectual a un paisaje más amplio — ese paisaje antes llamado "la sociedad en su conjunto” (Sarlo, “Intelectuales”) capaz de desbordar la especificidad de los campos. Por fragmentados y diseminados que hoy se encuentren los contornos de la "totalidad social”, ésta última seguiría actuando como una trama participativa de interrelaciones

leer a través de artículos publicados en las revistas argentinas El ojo mocho (dirigida por H. González) y Punto de Vista (dirigida por B. Sarlo). 
dinámicas entre prácticas, sujetos e instituciones: una trama cuya articulación de múltiples tramos compone la red pública de circulación de los discursos — una red que nos ofrece la amplitud de movimientos sin la cual el debate intelectual agota sus fuerzas en los restringidos límites del encierro profesional.

Es decir que, para B. Sarlo, los cruces entre “intelectuales” y “sociedad” pasan de dos maneras por el tema de la distancia. Por un lado, se trataría de recorrer la distancia que separa a la crítica de una red ampliada de interlocuciones sociales que debe exceder la figura del destinatario trazado por las especializaciones académicas, para generar necesarias "zonas de contacto” entre discurso intelectual y materias públicas. Por otro lado, se trataría de preocuparse por la distancia desde la cual enunciar la posición crítica (aunque esta distancia — lo afirma la misma B. Sarlo_ no es nunca enteramente calculable ${ }^{4}$ ) para que dicha posición no se encuentre ni demasiado cercana del objeto a criticar (caso en el cual el discurso de la crítica queda miméticamente cautivo de los reflejos más superficiales de la actualidad creada por los medios de masas) ni tampoco demasiado lejana de ese objeto (caso en el cual se separa demasiado de aquel horizonte mediano de comprensión social que busca afectar y transformar).

Medir la distancia entre "intelectuales” y "sociedad" para transitar por sus zonas intermedias en busca de una cierta comunidad de sentido, sería lo que H. González le reprocha a B. Sarlo en la polémica mencionada. Para él, ambas disposiciones implican buscar mediaciones, es decir, acomodos, entre dos escenas (la escena del texto crítico, la escena de la pragmática social de recepción del sentido) que no deberían nunca complacerse en estos acomodamientos y negociaciones, ya que el poder de la crítica — como fuerza de lenguage - radica precisamente en el efecto dislocante que la hace rebelde al término medio de la adecuación. Programar un juego de coincidencias entre estas dos escenas mencionadas mediante ajustes componedores para lograr eficacia en el diálogo con públicos mayoritarios, implicaría — para H. González- sacrificar la dimensión de resistencia negativa que conlleva toda escritura crítica en tanto escritura que, frente a los tratos y contratos de lo existente, debe permanecer insatisfecha, desconciliada. Según H. González, tomar demasiado en cuenta las circunstancias de recepción del discurso crítico y, además, pedirle a ese discurso que obedezca a parámetros de lectura masiva para ganar audibilidad social (teniendo que moderar así su fuerza de ruptura y dislocación) llevaría la crítica, pese a sus lúcidos contenidos progresistas, a convertirse en un simple "oficialismo de época”. El tránsito que ejecuta B. Sarlo, por ejemplo, en Escenas de la vida posmoderna contiene, para H. González, el peligro de "la progresiva conversión del intelectual crítico en intelectual progresista” (Montaldo 36), es decir, en un intelectual que, plegado a la ordenabilidad democrática, sólo sabe de moderación y de adecuaciones. Pensado así, el intelectual progresista sería aquél que pretende corregir las injusticias del presente pero que, al satisfacer la misma demanda de “instantánea legibilidad de sus consignas” (González, “Teoría con” 35) que persiguen los mercados de signos de la actualidad, no logra desarmar

${ }^{4}$ En un texto reciente, B. Sarlo reinterpreta la cuestión de la "distancia media” que le reprocha H. González, diciendo: "No existe entonces 'una buena distancia', una distancia justa: la práctica intelectual se caracteriza por el desajuste del lugar que se cree ocupar con el discurso y la autoridad atribuida al discurso. Los efectos del discurso intelectual del lado de la recepción , son prácticamente incontrolables" (Beatriz Sarlo, "Intelectuales, un examen” 10). 
ni subvertir las reglas de formulación y comprensión de un presente programado y diagramado por los medios en serie. Esta incapacidad del “comunicador lúcido-progresista” (González, “Teorías con” 35) de fracturar la sintaxis del presente con desmontajes de voz se debería a que dicho comunicador no se atreve a "tomar como problema la fabricación de lenguajes”, porque su realismo democrático lo obliga al requerimiento divulgativo de tener que "enviar todo significado o todo lenguaje a una prueba de inteligibilidad proporcionada por los medios de comunicación” (González, “Teoría con” 35).

Buscar mayor eficacia en el diálogo crítico con las manifestaciones del presente sin intentar quebrar los léxicos de su "estado de cosas"; forzar el entendimiento entre la crítica y sus universos de recepción social, tiene el problema de limar demasiado "las asperezas y disonancias” (González, “Teoría con” 35) que debe seguir exhibiendo la escritura crítica para distinguirse de la masa de los otros discursos estandarizados. Son, precisamente, estas asperezas y disonancias de tono y vocabulario las que pueden contradecir — con sus irregularidades - la serie homogeneizadora del mercado cultural. Si el mercado cultural aspira dominantemente a la transparencia y simpleza de mensajes que deben ser velozmente traducibles a la norma comunicativa del intercambio práctico, la crítica sólo podría burlar ese mercado de la denotatividad con palabras que requieren de un tiempo de demora para ser descrifradas en la complejidad de su volumen figurativo. Palabras que deberían causar la sensación de un cuerpo extraño en el universo de planitud comunicativa del resto de los mensajes circulantes, para que se cumpla la fuerza de alteridad-alteración con que la crítica logrará desuniformar los planos-de-representación de lo establecido por las discursividades oficiales.

\section{SABERES FUNCIONALES Y DISRUPCIÓN CRÍTICA}

La polémica que estoy usando como marco de referencia sugiere un enfrentamiento para retomar los términos que comparecen en ella, muchas veces tensionados en cada uno de los respectivos polos de argumentación- entre el realismo democrático de la crítica intelectual, por un lado y, por otro, la disrupción crítica de una palabra que se quiere inajustable. Pero más allá de la inscripción local de esta polémica, resulta tentador deslizar sus términos hacia el mundo de la actual producción académica y sus modelos de producción de saberes.

Son varias las reflexiones chilenas y argentinas que levantan su sospecha contra la dominante norteamericana de los estudios culturales, en nombre de una crítica a sus formas del discurso académico. Aunque formulados en distintos tonos y modos según los autores, los motivos del reclamo que algunos les dirigimos a los estudios culturales conciernen su modo de promover el funcionalismo explicativo de un saber que se reduce generalmente a la simple descripción de objetos listos, dispuestos y compuestos, de objetos ya sancionados por los diagnósticos de fin de siglo: massmediatización, globalización económica, multiculturalidad, etc. ${ }^{5}$ El funcionalismo explicativo del tipo de conocimientos que demandan los estudios culturales los haría difícilmente capaces de salirse de estos

${ }^{5}$ Para una discusión de este punto, ver el capítulo “Antidisciplina, transdisciplina y redisciplinamientos del saber” en Nelly Richard, Residuos y metáforas. 
ordenamientos pretrazados que reproducen el mapa de la globalización, con sus zonas de libre comercio entre disciplinas: unas zonas de conciliaciones prácticas entre saberes diferentes y complementarios que buscan extender y diversificar su comprensión de lo social y de lo cultural, pero sin querer poner en cuestión la lengua técnica y operativa del intercambio capitalista que también les sirve de pasaporte. Habría un exceso de realismo académico en los estudios culturales que sella el acuerdo entre la pragmaticidad de conocimientos de la investigación universitaria y las nuevas fuerzas económicas de administración de la cultura, sin casi dejar lugar para lo que desobedece provocativamente las clasificaciones de objetos fijadas por las agendas de investigaciones bien remuneradas. El predominio de un conocimiento funcionalizable que se justifica en la empiria del dato al que responden utilitariamente estas investigaciones, las volvería más bien incompatibles con el análisis de aquellas políticas y poéticas “menores” (en sentido deleuziano) cuyas líneas de fuga desvían el control normalizador de la globalización académica.

El funcionalismo de los estudios culturales les pide optimizar su saber para resolver lo más ejecutivamente posible las dificultades señaladas por el marco de problemas de la globalización capitalista, sin que ese saber pueda darse el lujo — teórico- de poner en cuestión la armadura de los lenguajes que condicionan sus investigaciones. Se ha consagrado así una industria del paper que deja obviamente fuera de sus trámites competentes, todo lo ligado a aquellas problemáticas formales y discursivas de una práctica del texto que caracterizaban antes a la formación humanística. Al sólo perseguir la manipulabilidad del sentido con vocabularios desapasionados, los estudios culturales han dejado de prestar atención a los descalces de sentido y juegos de la escritura que convocaban la palabra "teoría”. Ese saber de los estudios culturales ha marginado de su campo de intereses la dimensión metacrítica de una reflexión teórica sobre la escritura que elige meditar sus recursos a la palabra: la torsión reflexiva del lenguaje de la crítica que piensa la escritura al meditar sobre cómo dice lo que dice.

No está demás reparar en que estos reclamos al conocimiento funcional de los estudios culturales hechos desde la crítica del saber que expresan distintos críticos en Argentina y Chile, poseen inflexiones que son muy poco registradas en las discusiones de la academia internacional sobre la crítica latinoamericana. ${ }^{6}$ La actual sensación es que el mapa de los

\footnotetext{
${ }^{6}$ Estas inflexiones guardan el acento de una tradición formada por la teoría crítica, la crítica estética y el diálogo filosófico con el pensamiento cultural europeo. Por ejemplo, N. Casullo echa de menos "la herencia de pensamiento negativo" en los lenguajes positivizados de los estudios culturales que han borrado del presente toda marca de "dramaticidad". "El acoso, el peligro, frankfurtianamente, es clave para ensayar una resistencia negativa contra la lógica histórica racionalista capitalista” mientras "la utilización de un instrumental metodológico que dé cuenta de los 'dispositivos' de un producir cultural, o racionalice, ordene y exponga 'el objeto' desde una matriz casi importada del territorio periodístico, define parcamente los propósitos 'culturales', sin la menor preocupación de otras indagaciones teórico-críticas sobre los propios instrumentales de conocimiento, dentro de una lógica política y científica tecnoproductiva neoentendida ahora como 'irrebatible' curso del sistema" (Nicolás Casullo, Modernidad y cultura crítica 43-65). Por su parte, E. Grüner también defiende la radicalidad de la teoría crítica en contra de los acomodos pluralistas de los estudios culturales: "Que de la teoría crítica de la cultura — tal como podía postularla, por ejemplo, la Escuela de Frankfurtse haya pasado a los Estudios Culturales, es algo más que la simple adaptación de una moda norteamericana, o que la comprensible disputa por la inclusión en el mercado de los financiamientos
} 
estudios latinoamericanos en Estados Unidos tiende generalmente a desacentuar el problema de la teoría y de la escritura, o bien a desplazar su discusión hacia fuera de los ámbitos del latinoamericanismo, reservándolo para aquellos departamentos que gozan de reconocida autoridad para hablar — en inglés — sobre filosofías de la deconstrucción, teoría literaria o posestructuralismo. Es como si el latinoamericanismo debiera necesariamente huir de tales abstracciones y distracciones (la filosofía, la teoría y la escritura) para sólo dedicarse, empíricamente, a la sociología o la antropología de la cultura. No es de sorprenderse entonces que los estudios latinoamericanos padezcan los efectos, señalados por Román de la Campa, de separación y divorcio entre "las disciplinas de lo social dirigidas hacia la investigación empírica” por un lado y, por otro, lo que él llama "las nuevas humanidades orientadas hacia descalces discursivos” ("De la deconstrucción”).

Contrariamente a los efectos operados por esta división del trabajo que rige el campo latinoamericanista de Estados Unidos, los más recientes debates intelectuales en América Latina nos dicen que sí es posible mezclar los contenidos sociales de la historia de las ideas y de la teoría cultural, con una reflexión filosófica o estética sobre las problemáticas formales y discursivas del lenguaje de la crítica. Esto nos ocurre quizás porque el mapa universitario y sus trazados de campos son mucho más precarios y disgregados en América Latina que en el mundo de la academia internacional, posibilitando así mezclas irregulares y disonantes entre tradiciones entrecortadas. O bien porque las fracturas dictatoriales del Cono Sur han producido teorizaciones heterodoxas que desbordaron a la fuerza el cerco autorizado de las especializaciones disciplinarias, y porque — en estos contextos nuestrosel arte y la literatura aprendieron a repolitizar el gesto de la crítica desde los bordes cruzados de lo estético y lo ideológico. En todo caso, nos resulta más familiar, desde Chile o desde Argentina, estas mezclas de urgencias políticas, de pasiones intelectuales y de vocaciones de estilo que exceden el marco del profesionalismo académico y su separación entre lo estético y lo político, lo discursivo y lo operante, para cruzar preguntas ya no disociadas entre sí que remiten a la fuerza de intervención pública del discurso intelectual, pero sin descuidar las cuestiones de teoría y de escritura que siguen atravesando toda reflexión crítica y estética que busca contraponerse a los ordenamientos banalizadores de los recuentos de la actualidad. ${ }^{7}$ Insistir en estas cuestiones de teoría y de escritura habla de las ganas de desobedecer verbalmente la tecnicidad de aquella lengua sin imaginación que hoy triunfa en el nuevo paisaje socio-académico de la globalización comunicativa, subrayando la urdimbre reflexiva de una palabra que se concibe en permanente trance de significación en lugar de querer finalizar su trayecto útil en la simple administración de conocimientos — una palabra que se atreve a vagar por las orillas del concepto sin tener que sacrificar lo tenue en provecho de lo eficiente. Oponer resistencia comunicativa al flujo liso de la circulación capitalista, pasaría por rescatar la singularidad de este acto de escritura cuyo

académicos. Es, además de eso, el síntoma de la sustitución de un intento de puesta en crisis de las hegemonías culturales en su conjunto por la observación etnográfica de las dispersiones y fragmentaciones político-sociales y discursivas producidas por el capitalismo tardío” (Gruner 26-27).

${ }^{7} \mathrm{Al}$ decir "teoría” y "escritura”, me estoy refiriendo a la autoreflexividad de una prática del texto crítico que no se conforma con sólo analizar nuevos problemas conceptuales sino que desea, al mismo tiempo, trastocar las convenciones de habla que les dan rutinariamente a estos problemas su forma de discurso académico. 
relieve y opacidad desafían su sistema plano de equivalencias y traductividad generales de los signos.

En esta dirección se orienta, creo, la preocupación de H. González de "no escribir sobre ningún problema, si ese escribir no se constituye también en problema” (“Elogio” 29); de poner a prueba las fronteras de comunicabilidad de los mensajes y saberes ya aprobados por el mercado y la universidad para que surja de esta incomodación del sentido nuevas formas de ser, de ver y de leer. En esta dirección va también el reclamo de N. Casullo contra "el conocimiento satisfecho" del "intelectual funcionalizado, profesionalizado, academizado" de los estudios culturales y de las políticas culturales, y su deseo de una "crítica radical” a "la labor homologadora de los poderes comunicacionales” (Casullo 10). Esta misma dirección orienta la reflexión de F. Galende que nos advierte que "el pensamiento crítico no es sólo lo que vive en estado de disconformidad con el presente" sino lo que deja que su crítica del presente viva "el estupor y lo intempestivo" de una "otredad” de lenguajes (Galende).

Lo que hoy inquieta a una determinada región de la crítica latinoamericana tiene que ver, entonces, con esta necesidad de reinscribir, en el paisaje sociocomunicativo del conocimiento académico, los pliegues de una subjetividad crítica que hace de la teoría una autoreflexión sobre las puestas-en-forma del lenguage, sobre sus construcciones de sentido y sus modelajes expresivos, ${ }^{8}$ para afinar y refinar las armas de una crítica política e ideológica de la cultura que sea capaz de recuperar una cierta "dramaticidad de lo cultural" (Casullo) en contraste y oposición con los saberes positivizados de la burocracia académica. La teoría no puede renunciar a las torsiones de un lenguaje que se dobla críticamente sobre sí mismo para explorar los descalces de la representación. Renunciar a esta autocriticidad del lenguaje implicaría someterse al recuento simplemente descriptivo de una actualidad en satisfecha concordancia consigo misma, sin fisuras de significación por donde verbalizar el descontento o bien causar revuelos de extrañeza.

Pero son muchos los desafíos que convocan al crítico deseoso de salirse del protegido recinto del profesionalismo universitario (y de sus cuidados limites de no-interferencia) para poner a circular sus desacuerdos con el presente. Quiere demarcarse de la transparencia operacional de los saberes tecno-investigativos y de su mercado de las industrias culturales, pero sin que este separarse (idiomáticamente) del lenguaje de los medios exima a la crítica del tener que confrontarse activamente a las redes públicas de la actualidad mediante roces institucionales y fricciones de enunciados. Quiere criticar las redundancias mediáticas de la actualidad desde un lenguaje que no sea fácilmente recuperable por la simpleza y trivialidad de sus consignas y debe, entonces, autovigilar las condiciones de circulación de su discurso en los contextos de debate público para que las rutinas del sentido común no neutralicen la fuerza de desacomodo de la crítica, pero no puede dejar que los excesos de

\footnotetext{
${ }^{8}$ Decía R. Barthes: “me pregunto si, en última instancia, no podría identificarse teoría y escritura. La escritura, en el sentido actual que puede concederse a la palabra, es una teoría. Tiene una dimensión teórica, y a la vez ninguna teoría debe rehusar la escritura, ninguna teoría debe moverse únicamente en el interior de una pura 'escribancia', es decir, desde una perspectiva puramente instrumental respecto al lenguaje [...] La teoría sería un lenguaje que se observa a sí mismo en una especie de autocrítica permanente” (La teoría 9).
} 
vigilancia epistemológica del teoricismo académico terminen dejando inafectada la red material de agenciamientos prácticos que tejen las hegemonías culturales. Siente la necesidad de que su voz intervenga en el debate político-intelectual, pero sin renunciar al espesor teórico y reflexivo de una palabra encargada de producir rupturas de tono y quiebres de inflexión en la masa estandarizada de los discursos mediáticos. Desea proteger la dimensión de reserva y diferimiento críticos de la escritura —en oposición a la transitividad de los saberes directos que se agotan en la coyuntura de lo dado-, pero sin dejar que el margen de refractariedad que rodea la palabra sea tan total que la margine en un oscurantismo de la intraducibilidad anulando así los alcances institucionales de su polémica con la actualidad. ${ }^{9}$ Debe practicar el escepticismo de la duda frente a los excesos de optimismo comunicacional y los festejos de la "sociedad transparente" que desdramatizaron a la conciencia crítica, pero ese escepticismo de la duda no puede conducirlo a la abstención como única táctica de no-recuperación de la palabra porque ésta sería la mejor forma de dejar el presente tal cual.

Éstos son algunos de los desafíos hoy formulados por una determinada escena de reflexión crítica latinoamericana que pone en tensión saberes académicos y crítica del saber; razón crítica y vocación política; intervención socio-intelectual y reserva de pensamiento negativo. Las preguntas suscitadas por estas tensiones dilemáticas son difíciles de responder y, en el caso de tener respuestas, sus límites de validez o eficacia no están garantizados. Quizás “corresponda a cada situación de discurso las estrategias por las que se enfrenta esta oposición” entre “comunicación” y “escritura” (Sarlo). Definir estas estrategias le permite al intelectual crítico conjugar la función del “analista y del utopista” (Barthes, Le grain 187): del que analiza el juego entre codificaciones de poder y desarreglos críticos en función de "las necesidades tácticas de la guerra de sentidos" (Barthes) que atraviesan el campo de batalla de la cultura, y que potencia la virtualidad contrahegemónica de las líneas de descalce (de no-coincidencia) que abren textos, subjetividades sociales e imaginarios culturales, a nuevas poéticas y políticas de la crisis.

Quise subrayar aquí el modo en que estas tensiones entre lo crítico-estético y lo político-cultural obsesionan a ciertas reflexiones de hoy en Chile y Argentina, porque me parece que, su misma irresolución y sus desgarros, pueden resultar más apasionantes que el catálogo de los saberes-en-orden adquiridos por los estudios de la cultura que desfilan en muchos congresos internacionales tratando de rearticular sus competencias en la misma lengua de la operatividad que utiliza la globalización capitalista.

\footnotetext{
${ }^{9}$ Estas preguntas han sido trabajadas por W. Thayer quien las enuncia diciendo que, para toda escritura crítica atenta al problema poético del idioma de la crítica, "el peligro es reponer en lo que se "dice” lo que se quiere desdecir”: “¿Cómo, en qué idioma, no hablar contextualmente del contexto? ¿Cómo, en qué idioma, no hablar categorialmente de las categorías que se ponen en crisis? ¿Cómo, en qué idioma, no hablar la lengua de la familia y ser escuchado por ella ? ¿Cómo no hablar, por último, y ser oído ? ¿Y cómo hacerse oír sin dejarse asimilar, ni siquiera por uno mismo ?” (Willy Thayer, “Una épica deconstructiva” 57).
} 
Barthes, Roland. Le grain de la voix. Paris: Editions du Seuil, 1981. et al. La teoría. Barcelona: Anagrama, 1971.

Campa, Roman de la. "De la deconstrucción al nuevo texto social: pasos perdidos o por hacer en los estudios culturales latinoamericanos”. Nuevas perspectivas desde/sobre América Latina: el desafío de los estudios culturales. Mabel Moraña, ed. Santiago: Editorial Cuarto Propio/Pittsburgh: Instituto Internacional de Literatura Iberoamericana, 2000. 77-95.

Casullo, Nicolás. Modernidad y cultura crítica. Buenos Aires: Paidós, 1998.

Galende, Federico. “Un desmemoriado espíritu de época”. Revista de Crítica Cultural 13, (Santiago, noviembre 1996): 52-55.

González, Horacio. “Teoría con nombre propio”. El ojo mocho 3 (Buenos Aires, 1993). "Elogio del ensayo”. Últimas funciones del ensayo. Revista Babel 18 (Buenos Aires, agosto 1990) 29.

Grüner, Eduardo. "El retorno de la teoría crítica de la cultura: una introducción alegórica a Jameson y Zizek”. Estudios culturales. Reflexiones sobre el multiculturalismo. Buenos Aires: Paidós, 1998. 26-27.

Montaldo, Graciela. "Intelectuales y artistas en la sociedad civil argentina en el fin de siglo”. (Working Paper N. 4) 1999. The University of Maryland, College Park.

Pagni, Andrea y Erna von der Walde. “¿Qué intelectuales en tiempos posmodernos? o de ¿cómo ser radical sin ser fundamentalista? Aportes con una discusión con Beatriz Sarlo”. Latinoamerika studien 36 (Frankfurt, 1995).

Podlune, Judith. "Beatriz Sarlo/Horacio González: Perspectivas de la crítica cultural”. Las operaciones de la crítica. Alberto Giordano, María Celia Vásquez, comps. Rosario: Beatriz Viterbo Editora, 1998. 67-78.

Richard, Nelly. Residuos y metáforas; ensayos de crítica cultural sobre el Chile de la Transición. Santiago: Editorial Cuarto Propio, 1998.

Sarlo, Beatriz. Escenas de la vida posmoderna; intelectuales, arte y videocultura en la Argentina. Buenos Aires: Ariel, 1994.

“Intelectuales, un examen”. Revista de Ciencias Sociales 5 (Bogotá, enero 2000). “Intelectuales: ¿escisión o mímesis ?”. Punto de Vista 25 (Buenos Aires, diciembre 1985): 1-6.

Thayer, Willy. “Una épica deconstructiva”. Revista de Crítica Cultural 9 (Santiago, noviembre 1994): 57.

Volumen LXVI

Octubre-Diciembre 2000

Número 193 